\title{
RESEARCH DIRECTIONS AND THE MOST RELEVANT ACHIEVEMENTS OF CHEMISTRY RESEARCHERS IN THE REPUBLIC OF MOLDOVA FOR THE PERIOD OF 2004-2007
}

The first International Conference organized by the Chemical Society of Moldova has taken place in the early October 2003. Following are the most important research directions, objectives and realizations, achieved by different institutions involved in chemical research during the period of 2004-2007, presented in a very concise form.

The members of the Chemical Society of the Republic of Moldova perform investigations in various fields of modern chemistry: inorganic and bioinorganic, analytical and ecological, organic and bioorganic, physical and quantum chemistry. These investigations are performed in the 7 laboratories of the Institute of Chemistry of the Academy of Sciences of Moldova (ASM), the only one chemistry research institution in the country, as well as in other Academic Institutions (Institute of Genetics and Plant Physiology, Institute of Applied Physics, National Institute of Ecology) and University Centers like Scientific Center "Ecological and Applied Chemistry" from the State University of Moldova (the only one center of this profile in Moldova), at the Faculty of Chemistry and Chemical Technology of Moldova State University which includes the Chair of Inorganic and Physical Chemistry, Chair of Analytical and Organic Chemistry, Chair of Industrial and Ecological Chemistry, in other universities: Technical University of Moldova, State Medical and Pharmaceutical University "N. Testemițanu", State University of Tiraspol and State Agricultural University of Moldova. All the enumerated institutions are located in Chisinau. Certain research directions have been confirmed and gain ground in these institutions. Some of them locate scientific schools, recognized not only in Moldova but abroad too. Both fundamental and applied research is performed, that are important for the Moldovan National Economy.

The Republic of Moldova does not possess relevant minerals resources. The main branch of economy is agriculture and agricultural processing industry. Annually, the agricultural processing provides different wastes that can serve as renewable raw material for the production of different natural compounds. A part of these compounds are interesting as biologically active substances. The rest of them can be used and actually are used as raw material for the target synthesis of substances with potential applications in pharmaceutical, cosmetic, perfumery, food, wine and tobacco industries. Such investigations are realized in several institutions.

A positive evolution in the field of essential oil investigation and production is noticed in the recent years. This branch was almost destroyed after the disintegration of the Soviet Union. But the climatic conditions in Moldova are favorable for cultivation of essential oil producing plants.

Another research direction of primordial importance relates to ecology issues, first of all the problem of water resources which are rather limited in Moldova. Several scientific organizations work in this field and study different aspects of the problem: surface and underground waters, new technologies for purification of natural waters from undesirable contaminants are being elaborated (hydrogen sulfide, fluorine and iron salts, etc.), as well for treatment of residual waters.

One of the oldest research directions of chemical investigations, adopted broadly in several institution of Moldova, relates to the chemistry of coordination compounds.

The last 2-3 years have witnessed positive changes in the field of scientific research. But anyway, the science in general and chemical science in particular meets some difficulties, due to the absence of relevant equipment, limited access to the information, low level of salary. As a result, the field of research still remains a non-prestigious field of human activity for the younger generation. Under these circumstances it is very important for us to establish scientific collaboration with colleagues from abroad, including European Union, USA, Israel and other countries within collaborative bi- and multilateral projects (INTAS, NATO, CRDF/MRDA, Humboldt, DAAD, etc.). One of the basic priorities of this collaborations is establishing of new collaborative relationships with our colleagues from abroad and extinction of those existent, first of all in European Union in order to integrate in the 7-th framework program. We will update below in a concise way the basic directions of fundamental and applicative research, as well as the more important results achieved by each chemistry research unit from Moldova during the period of 20042007, after the first Conference of the Chemical Society of Moldova. It is intended to facilitate in such a way mutual contacts and collaborative relations with our colleagues from abroad. It is noteworthy mentioning that preparation of highly qualified specialists takes place in the same institutions that are involved in the chemistry research. 


\section{Institute of Chemistry of the Academy of Sciences of Moldova}

\section{Laboratory of Coordination Chemistry}

A range of coordination compounds ( 150) of $3 \mathrm{~d}$ transition metals (such as $\mathrm{V}, \mathrm{Cr}, \mathrm{Mn}, \mathrm{Fe}, \mathrm{Co}, \mathrm{Ni}, \mathrm{Cu}, \mathrm{Zn}$ ) with such organic ligands as mono- and dicarboxylic acids, thiosemicarbazide, $\alpha$-dioximes, bipyridile, imidazole, etc, have been synthesized and investigated. Using the template synthesis, mono-, bi- and polynuclear macrocyclic compounds with an open profile were obtained. New carboxylate classes and types have been obtained; among them were found compounds with such potential useful properties as single molecule magnets, ferro- and antiferromagnets, catalysts for the oxidation processes and stimulators of biosynthesis in microorganisms. The stimulator properties are characteristic for cobalt and copper compounds, i.e. cobalt (III) dioximates with fluorine containing anions and compounds of $3 \mathrm{~d}$ metals with tetradentate ligands based on S-alkylisothiosemicarbazones of aromatic aldehydes and $\beta$-diketones. Some compounds demonstrated non-linear optical activity and can be used in optical electronics. A number of colored complexes of $\mathrm{Ni}(\mathrm{II})$ and $\mathrm{Co}(\mathrm{II})$ can serve as effective pigments for coloring the plastics.

(Head of laboratory, dr. hab. sci., prof. Bulhac I.)

\section{Laboratory of Bioinorganic Chemistry}

During the 2004 to 2006 period the laboratory of bioinorganic chemistry of the ASM continues to synthesize and study the homo- and heteronuclear oxo-carboxylates complexes containing d-, s- and f- metals. For the first time there were obtained a new set of tri-, tetra-, hexa-, nona, dodeca- and polynuclear complexes with the fragments $\left\{\mathrm{Fe}_{2} \mathrm{MO}\right\},\left\{\mathrm{Fe}_{3} \mathrm{LnO}_{2}\right\},\left\{\mathrm{Fe}_{4} \mathrm{Ca}_{2} \mathrm{O}_{2}\right\},\left\{\mathrm{Mn}_{10} \mathrm{Fe}_{2} \mathrm{O}_{12}\right\},\left\{\mathrm{Mn}_{10} \mathrm{Ln}_{2} \mathrm{O}_{9}\right\},\left\{\mathrm{Cu}_{2}\right\},\left\{\mathrm{Nd}_{2}\right\},\left\{\mathrm{Sm}_{\mathrm{n}}\right\},\left\{\mathrm{De}_{\mathrm{n}}\right\},\left\{\mathrm{Fe}_{3} \mathrm{O}\left(\mathrm{Fc}_{6}\right\},\left\{\left(\mathrm{Ba}_{2} \mathrm{Fe}_{2}\right)_{\mathrm{n}}\right\}\right.$, $\left\{\left(\mathrm{FeSr}_{2}\right)_{\mathrm{n}}\right)$, where $\mathrm{M}=\mathrm{s}-, \mathrm{d}$-; $\mathrm{Ln}=\mathrm{f}$-elements; $\mathrm{Fc}=$ carboxyferrocenyl. The obtained complexes were studied by different physical methods: X-ray, IR, UV-VIS, EPR, luminescence and Mossbauer spectroscopy, thermogravimetry and magnetochemistry. By introduction of monodentate ligand with different affinity to coordinated metals in heterotrinuclear clusters with $\left\{\mathrm{Fe}_{2} \mathrm{MO}\right\}$ core and having the properties to form the intermolecular bonds it was demonstrated the possibility to localise the position of heterometal in this triangle.

Using the Schiff bases obtained by condensation of 3-formylsalycilic acid, 2-oxy-3-carboxynaftaldehide, oxy-acids of Krebs cycle with different ammines the new mono-, or polynuclear coordination compounds of d- and f- elements were synthesized and characterized.

The synthesized coordination compounds were tested with the purpose to obtain new biological active substances for biotechnology and physiology of plants. Several of the obtained compounds stimulated biomass accumulation of the strains of Rhizopus arrhizus F67, Spirulina platensis, as well as increasing the content of biologically active compounds like aminoacids, carotenoids, iron derivatives. Some of investigated substances showed growth stimulating properties for plants.

(Head of laboratory, corresponding member of the ASM, dr. hab. sci., prof. Turtă C.I.)

\section{Laboratory of Quantum Chemistry and Chemical Kinetics}

In the field of quantum chemistry the mechanism of the oxygen and phosphor molecules activation in the processes of coordination to the transition metals compounds in numerous important chemical reactions in chemistry, biology, medicine and the environment have been revealed. Using the vibronic theory of small molecules activation in the combination with the ab initio calculations a series of coordinative compounds of the transit metals ( $\mathrm{Mn}, \mathrm{Fe}, \mathrm{Co}, \mathrm{Cu}$, $\mathrm{Rh}, \mathrm{Ir}$ ) with a variety of ligands (porphirines, phtalocianines, fenantroline, pyridine etc) have been studied.

It was demonstrated that the oxygen activation is due to the partial transfers of the charge to and from the dioxygen orbitals, and not to the total charge transfer. This explains why some compounds add the dioxygen in the reversible way, while in other cases the coordination is reversible. The results obtained contribute to the understanding of the dioxygen and phosphor activating processes.

Based on quantum chemical calculations the theory of the exchange interaction of the electrons transfer and the magnetic properties in poly-nuclear systems was developed.

(Head of laboratory, dr. hab. sci., prof. Ogurtsov I.Ya.)

\section{Laboratory of Ecological Chemistry}

During the period between 2004-2007 new methods for obtaining a number of adsorptive materials for environmental and health protection have been elaborated on the basis of secondary materials after grape processing. Their phisicochemical properties have been studied. Carbonic adsorbents and catalysts have been obtained from vegetal byproducts (nutshells, peach and plum stones etc.). Adsorptive properties of cross linked adsorbents based on local diatomites and chemically modified ones have been studied. Technologies for underground and surface waters purification have been elaborated in order to eliminate hydrogen sulfide and nitrate contaminants. New plaster mixtures have been elaborated and implemented in the field of civil engineering. A new preparation has been obtained from the vinery wastes and it showed bold antifungal and antimicrobial properties.

(Head of laboratory, dr. hab. sci., prof. Lupaşcu T.) 


\section{Laboratory of Physico-Chemical Methods of Research and Analysis}

An accumulation analysis method in adsorptive catodic stripping voltametry has been developed. The proposed procedure is performed in the presence of thiosemicarbaside derivatives, including application of modified carbon fiber electrodes. Methods have been elaborated for the determination of $\mathrm{Cd}, \mathrm{Cu}, \mathrm{Pb}, \mathrm{Ni}$ in the food products and natural waters, including Nistru river. Investigations have been performed in order to evaluate the electrochemical behavior of systems metal - oxidation agent in the presence of new organic reagents for amplification of the analytical signal. Determination procedures have been elaborated using the method with anodic stripping for metals like $\mathrm{Hg}, \mathrm{Cd}, \mathrm{Pb}$, $\mathrm{Zn}, \mathrm{Tl}$. Modification of the microelectrode by deposition of a nanolayer of mercury has led to a considerable method sensitivity and selectivity increase. Using this method it was possible to determine $\mathrm{Tl}$ in the Nistru river water and sediments and $\mathrm{Cd}$ in the soil samples.

(Head of laboratory, dr. Chiriac L.)

\section{Laboratory of Organic Synthesis}

The investigations in the field of organic synthesis revolve around the targeted synthesis of combinatorial libraries of heterocyclic bioactive compounds, based on the computational SAR studies. Following work is performed to estimate the match between forecasted and observed physiological effects. New heterocyclic compounds with cognition enhancing, anxiolitic and anticonvulsant properties have been prepared on the basis of benzoic acids hydrazides. A special attention has been paid to the synthesis of compounds with antituberculosis activity, a malady that poses problems both in the Republic of Moldova and other countries too. More then 40 new substances have been obtained from the 5-aryl-2-thio-1,3,4-oxodiazol series with this purpose and tested in the USA. The in vitro tests results have demonstrated a good correlation between forecasted and real activity. Four compounds with relevant activity have been selected for advanced studies. A number of compounds with psychotropic activity has been synthezed on the basis of izatine and oxazolidines. Two compounds from this series have shown higher activity then generic pharmaceuticals "Medazepam" and "Piracetam". Derivatives of 1,3-imidazole and 1,2,4-thiazole with antifungal activity have been obtained.

(Head of laboratory, dr. hab. sci., Macaev F.Z.)

\section{Laboratory of Terpenoid Chemistry}

The field of natural product chemistry and synthesis has a long history in the Institute of Chemistry. Current efforts have been oriented to the synthesis of terpenes with specific structure and properties. The range of the investigated substrates spreads from monoterpenes to polyprenols. A special emphasize was placed on the synthesis of a series of sesquiterpenoids with drimanic structure (hydrocarbons, alcohols, ketones, lactones, esters and polyols). An original method for the fotodehydrogenation of $\alpha, \beta$-unsaturated cyclic ketones to $\alpha, \alpha$-dienones has been elaborated.

The synthesis of austrodoral and austrodoric acid, natural norsesquiterpenoids of marine origine, has been performed for the first time. This work provided a new approach to the highly functionalized perhydrindane skeleton and confirmed the structure and stereochemistry of the corresponding natural compounds.

The natural bioactive diterpenoid $\omega$-hidroxigeranylgeraniol has been obtained by two different approaches.

Onoceranic triterpenes have been prepared by a short and straightforward procedure from readily available homodrimanic compounds.

The method of cyclic terpenoids preparation by superacidic cyclization has been developed on more complex substrates. Investigation of $\omega$-hidroxigeranylgeraniol derivatives cyclization has led to the elaboration of a new biomimetic procedure for the synthesis of sacculatanic diterpenoids. Studying the superacidic cyclization of linear sesterterpenic esters it was stated that the configuration of the internal double bond allows controlling the structural selectivity of the reaction, simulating the biogenetical behavior of natural polyprenols. It was demonstrated on the other hand that the superacidic cyclization reaction of the sesterterpenic derivatives can be also directed by a specific placement of a phenylsulfonyl group in the certain positions of the aliphatic chain.

It was established that the superacidic cylization of terpenoids can be realized in the ionic liquid medium. Substrates with functional groups stable to acidic conditions showed excellent results in these experiments.

(Head of laboratory, academician of ASM, dr. hab. sci., prof. Vlad P.F.)

\section{Institute of Genetics and Plant Phisiology of the Academy of Sciences of Moldova}

\section{Laboratory of Natural Bioregulators}

Natural products of steroid structure are studied for a long time in Moldova. A series of more then 50 steroidal glycosides of spirostanolic and furostanolic structures have been isolated from 3 species of plants of Solanaceae family (Hyoscyamus niger L., Physalis alkekengy L., and Physalis leguminose L.). These compounds contain as aglicones tigogenine, diosgenine and gitogenine, whyle their shugar chain in the C-3 position contains from 2 to 5 monozaharidic residues with linear or branched structure. Among the isolated spirostanolic oligozides there are compounds which 
possess antibacterial, antimicrobial and antifungal activity. The preparation "Pacovirin" has been implemented in pharmaceutical production for the treatment of viral hepatitis. Some furostanolic glycosides showed plant growth regulator properties.

(Head of laboratory, dr. hab. sci., prof. Chintea P.C.)

\section{Institute of Applied Physics of the Academy of Sciences of Moldova}

\section{Tadeusz Malinowski Laboratory of Physical Methods of Solid State Investigation}

The laboratory is involved in structural study of different classes of chemical compounds. The basic priority is given to crystal engineering of supramolecular systems. New results oriented to the construction of heterometalic (d/f) complexes based on pyridine- carboxylic acids have been obtained during the recent years. These complexes are potential candidates for molecular electronic devices. Besides, bioactive binary and mixed complexes of transition metals with $\alpha$-aminoacids have been investigated. The structure of layered systems with nano-dimentional cavities and channels has been studied with the perspective of obtaining on their basis of inclusion compounds with hydrogen, methane and other gases. The investigations of week interactions in host-guest complexes, especially those on the basis of crown ethers and azamacrocycles have been continued. The dependence structure-properties for the biologically active compounds and multi-component crystals including pharmaceutically active components is investigated too.

(Head of laboratory, dr. Simonov Yu.A.)

\section{Laboratory of Materials Electrochemical Treatment}

The main scientific activity has been concentrated on the problems of electrochemical dimensional micro- and nanotreatment and also to the development of methods of obtaining of the electrochemical coverings possessing unique functional properties. Essentially new method of determination of throwing power of electrolytes in controllable hydrodinamical conditions was proposed and investigated. Conditions of controlling micro- and macro distribution of current and rates of machining during electrochemical micromachining in presence of photoresist masks on nonuniform surfaces are developed, including under pulse conditions.

Influence of surface heat production on electrodeposition rate, on current density - deposition rate dependences; on technological parameters (first of all, for the case at chromium plating), including electrolyte throwing power and structure of the deposited layers were investigated for electrodeposition of chromium in standard chromic electrolyte and Co-W alloys in citrate electrolyte, at various bulk electrolyte temperatures and current densities of constant and pulse currents. It is shown, that the unipolar pulse current application increased the throwing power of standard chromic electrolyte.

The laboratory develops also cooperative projects with several IAP laboratories, Chisinau Technical University and foreign institutions. Electrochemical methods of obtaining nanocomposition, low-dimensioned objects and nanostructures with reference to the solution of problems of efficiency increasing of alternative energy sources and controlling of functional properties of surfaces were developed within these cooperations.

(Head of laboratory, corresponding member of the ASM, dr. hab. sci., prof. Dicusar A.I.)

\section{Laboratory of Substances Electroflotation}

The activation regularities of alluminium hydroxides and of some natural mineral sorbents from Moldova have been studied under different conditions, including electrical and thermal treatment and treatment with calcium oxide. The principles of tuning the properties of these adsorbents have been revealed. Active adsorbents with different broadly ranging structures and superficial properties have been obtained. The action of electrolysis gases on the superficial properties of mineral adsorbents has been studied. It is proposed to use these treated adsorbents for the elimination of some organic substances present in underground waters. Some toxic compounds have been eliminated from aqueous solutions by electrodialysis method. It was demonstrated that modified adsorbents can be utilized for the elimination of some noxious colorants and fluorine compounds from natural and residual waters. The mechanisms of fixing these compounds on the surface of the modified adsorbents have been clarified.

(Head of laboratory, dr. Zelențov V.I.)

\section{Institute of Ecology and Geography of the Academy of Sciences of Moldova}

\section{Laboratory “Quality of the Environment”}

The ecological state of Moldova aquatic resources has been evaluated. Advanced methods and technologies have been elaborated for the liquid systems purification. The factors that cause equilibrium changes in the system watersuspensions and water quality parameters have been evaluated. Their autopurification capacity has been correlated to the organic substances content. The influence of natural waters alkalinity and acidity on the suspension and colloid substances coagulation has been determined. The current state of Prut river effluents has been estimated. It was shown 
that industrial and agricultural pollutants are present in the boundary effluents and they inhibit the autopurification and nitrification processes. The local transboundary pollution burden has been calculated. A total number of 39 ISO standards have been recommended for implementation as national standards of water quality monitoring.

(Head of laboratory, dr. Tărîță A.)

\section{State University of Moldova. Faculty of Chemistry and Chemical Technology}

\section{Research Center “Applied and Ecological Chemistry” \\ Laboratory "Redox and catalytic processes in food products and water" and Industrial and Ecological Chemistry Chair}

A new procedure for tartaric acid and its derivatives obtaining from winery secondary products has been elaborated using liquid anionites for the tartaric acid extraction. The extraction process mechanism has been studied on model and real systems (wine yeasts, cognac winace) and a pilot-plant for tartaric acid production has been assembled.

$\mathrm{N}$-nitrosoamines formation reaction as well as the nitrozation process inhibition have been studied by application of different natural and synthetic inhibitors, including those obtained from tartaric acid. Investigation of redox processes that take place in model and real systems has served for the elaboration of combating and prevention methods of their negative impact by natural biologically active substances promoted inhibition of nitrozation reactions that take place in food products, tobacco and humans. Electrochemical methods for nitrate and nitrite elimination has been elaborated for natural waters purification.

Following studies are also oriented on the elaboration of physico-chemical methods for diminishing the concentration of textile dies in residual waters.

(Scientific supervisor academician of ASM, dr. hab. sci., prof. Duca Gh., head dr. Gonța M.)

\section{Laboratory "Electrochemical Processes and Ecologically Clean Production”}

Methods for water purification have been elaborated and refined, basing on purification intensification by different physical actions. Study of photocatalitic and oxidoreductive degradative purification of water from organic persistent pollutants has been performed. There were elaborated electrochemical purification methods of natural and residual waters, as well as sorptive and membrane water conditioning technologies. Intensification of the pollutants destructive processes has been effected by microbiological and biochemical pathways. These approaches were considered in the production of alternative fuel sources like biogas from wastewaters and winery wastes. Electrochemical and chemocatalitic processes for reduction of d-metals from solutions leading to alloys have been studied. The research has included also catalytic purification processes of different gaseous pollutants.

(Scientific supervisor academician of ASM, dr. hab. sci., prof. Duca Gh., head dr. Covalev V.)

\section{Laboratory "Atmosphere Protection"}

The influence of the homogeneous catalyst "Biofriendly" on the pollutant emissions originated from internal combustion engines has been studied. It was established that the content of carbon monoxide in the exhaust shows a 1.5-3 fold decrease, nitrogen oxides show a 1.3-1.6 fold decrease and methane shows a 1.4-1.6 fold decrease. The amount of smoke-black which contains carcinogenic hydrocarbons also decreases. The gasoline consumption is reduces by $10 \%$ and of the diesel fuel by $15 \%$. Implementation of the homogeneous catalyst will lead to the improvement of the air basin in the Republic of Moldova.

Investigations of natural gas combustion in an electric field have been performed. It was demonstrated that application of a $12 \mathrm{kV}$ tension at $32 \mathrm{~mA}$ improves the combustion yield by increasing flame temperature, reduces carbon monoxide content in the exhaust from $1.2 \%$ to $0.012 \%$ and saves $5 \%$ of fuel. A semiconducting sensor for the determination of carbon monoxide has been elaborated and tested.

(Scientific supervisor academician of ASM, dr. hab. sci., prof. Duca Gh., head dr. Crăciun A.)

\section{Laboratory "Ecological Chemistry of Aquatic Systems"}

Autopurification processes of both model and various field aquatic systems have been studied. Model studies included oxidation processes of some organic substances (benzoic and citric acids, cisteine and hydrochinone) catalized by $\mathrm{Cu}^{2+}$ and $\mathrm{Fe}^{3+}$ ions in the presence of oxygen and hydrogen peroxide. New methods for surface water quality estimation have been approved (redox state and autopurification kinetic parameters). New informational criteria for the estimation of ecological state of natural waters have been elaborated. The state of the Nistru river water has been investigated and traditional hydrochemical parameters as well as their redox state have been determined. It was confirmed that the redox 
state of the natural waters and kinetic parameters can serve as indicators for the water quality estimation and forecasting dangerous consequences following the changes in the redox state and kinetic parameters. It was established that for the Nistru river waters season changes in the redox state is a characteristic feature and hydrogen peroxide concentration $\left(\sim 10^{-7}\right)$ is not sufficient for an efficient realization of water autopurification processes which negatively influence the hydrobiota. The influence of some pesticides on water autopurification process has been investigated.

(Scientific supervisor academician of ASM, dr. hab. sci., prof. Duca Gh., head dr. Goreaceva N.)

\section{Analytical and Organic Chemistry Chair}

New thiosemicarbazones of 8-chinolinaldehyde have been obtained and new copper and palladium coordination compounds have been synthesized on their basis. Their biological activity and influence of substituents on the optical properties of copper complexes have been tested. The magnetic behaviour of copper binuclear complexes has been interpreted. It was established that the investigated thiosemicarbazones amplify their antibacterial properties on complexation with copper (II) and palladium (II). Membranes for potentiometric sensors have been created for the determination of perchlorates and nitrates. The target oriented transformation of S-methylthiosemicarbazone of salicylic aldehyde has been studied in the presence of sodium tetranitropalladate. The nitrosoamidation reaction has been described for the first time. The ligand assembled by thioamide group condensation is tridentate and condenses with the O,N,N atom set. Organic compounds have been obtained on the basis of isothiocyanatochalcones. A series of work relates to the synthesis and study of monomers and binary and ternary copolymers based on carbazolylmetacrilate with the aim of producing different organic semicinductors used in the optical information recording.

(Head of chair, dr. Dragalina G.)

\section{Inorganic and Physical Chemistry Chair}

There have been elaborated synthesis methods of new coordination compounds of $\mathrm{Co}, \mathrm{Ni}, \mathrm{Cu}$ and $\mathrm{Zn}$ with thioand semicarbazones, hydrazones and Schiff bases of substituted salicylic aldehydes and pyridine-2-carboxialdehyde. New mono- and heterometalic coordination compounds of $\mathrm{Bi}$ (III) and $\mathrm{Cr}$ (III) have been obtained using as ligands nitrilotriacetic, $\beta$-hydroxiethyl-iminodiacetic, antranylodiacetic and ethylenediamine-tetraacetic acids with elements from s- and d-element blocks ( $\mathrm{Mg}, \mathrm{Ca}, \mathrm{Sr}, \mathrm{Ba}, \mathrm{Mn}, \mathrm{Co}, \mathrm{Ni}, \mathrm{Cu}, \mathrm{Zn}$ etc.), their composition and structure have been established. The isomerisation mechanism of cobalt (II) octahedral complexes has been established. The biological activity of these substances has been tested. Some of compounds showed anticancer and antimicrobial activity. The heterometalic compounds of $\mathrm{Bi}$ (III) have high specific resistance $\left(10^{14}-10^{15} \mathrm{Ohm} \cdot \mathrm{cm}\right)$ and can serve as dielectric materials. Some chromium complexes can be used as molecular magnets.

A series on natural and synthetic adsorbents have been obtained and studied as selective catalysts for potable and residual water purification, stabilization of brute wines and juices.

(Head of chair, corresponding member of the ASM, dr. hab. sci., prof. Gulea A.)

\section{Technical University of Moldova. Chair of Chemistry}

Investigation of natural products is aimed to isolation of biologically active compounds from accessible natural sources. Efficient methods for the isolation and purification of hialuronic acid are considered. It is a biologically active compound found in different sources of animal origin with specific properties and could be used for production of new derivatives and compositions with potential application in food industry, pharmaceutical and cosmetics production. It is noteworthy mentioning that existing hyaluronic acid production and purification methods does not allow its broadly implementation.

Another research direction consists in the elaboration of technologies for preparation of iodine enriched products. Sunflower oils iodination product is used as iodine source. A procedure for the production of iodine fortified lactoacid products has been elaborated.

(Head of chair, dr. Verejan A.)

Tiraspol State University. Faculty of Chemistry and Biology

\section{Chair of Chemistry}

A series of more then 50 new $\mathrm{Co}(\mathrm{III})$ dioximates containing florous anions $\left(\left[\mathrm{BF}_{4}\right]^{-1},\left[\mathrm{PF}_{6}\right]^{-1},\left[\mathrm{SiF}_{6}\right]^{-2},\left[\mathrm{ZrF}_{6}\right]^{-2},\left[\mathrm{TiF}_{6}\right]^{-2}\right.$, $\left[\mathrm{AlF}_{6}\right]^{-3}$ etc.) have been synthesized and studied. Dioximates have been obtained, where the complex cation charge is compensated simultaneously by two different anions. Some of the obtained compounds stimulated or stabililized biosynthetic processes in some fungal strains of genus Rhizopus and Aspergillus under unfavorable activity conditions.

The department participate in the realization of investigations of underground aquatic sources quality in 
Chisinau, Ungheni and other rural localities. The content of a number of metals ( $\mathrm{Fe}, \mathrm{Zn}, \mathrm{Cu}, \mathrm{Cr}, \mathrm{Ni}, \mathrm{Pb})$ and nitrates and mineralization degree has been determined.

(Head of chair, dr. Corobceanu E.)

\section{N. Testemitanu Medical University of Moldova. Chair of Chemistry}

The kinetics and reaction mechanism of catalytic homogeneous decomposition of hydrogen peroxides promoted by $\mathrm{Mn}(\mathrm{II})$ coordination compounds with $o$-fenantroline and $\alpha, \alpha$-dipyridil have been studied. The reaction mechanism has been suggested for these processes and further confirmed experimentally. It was demonstrated that the studied catalytic reactions proceed via a chain ion-molecular mechanism. The possibility of using the studied catalytic systems for determination of macro- and micro-quantities of $\mathrm{Mn}$ in homogenous phase has been demonstrated. The catalytic properties of coordination compounds of $\mathrm{Fe}(\mathrm{III})$ and $\mathrm{Mn}$ (III) with $o$-fenantroline and $\alpha$, $\alpha$-dipyridil has been studied in several periodate promoted redox reactions.

(Head of chair dr. hab. sci., prof. Tighineanu I.)

\section{State Agricultural University of Moldova. Chair of Chemistry}

The Chair of Chemistry has performed collaborative research jointly with the laboratory of quantum chemistry and chemical kinetics of the Institute of Chemistry of ASM. The process of white phosforus activation under the action of $\mathrm{Ni}$ and $\mathrm{Cu}$ coordination compounds has been studied. The secondary metabolites of red pepper Capsicum Annuum L. have been studied. The typical pepper metabolites like capsaitinosides, glycoalcaloids and steroid glycosides have been extracted and characterized.

(Head of chair, dr. Gorgos V.)

In summary, the results of the research activity in the field of chemistry have been materialized by publication of 440 articles in international editions and 235 papers in local editions. There were also 816 presentations at international conferences and 232 at local scientific meetings. 222 patents have been obtained. $15 \mathrm{Ph} . \mathrm{D}$. and 2 habilitation theses have been successfully presented.

Academician Pavel F. VLAD

President of the Chemical Society of Moldova

Academician Gheorghe DUCA President of the Academy of Sciences of Moldova 